\title{
On the nature of fear of falling in Parkinson's disease
}

\author{
S. Rahman ${ }^{\mathrm{a}, 1}$, H.J. Griffin ${ }^{\mathrm{a}, \mathrm{b}, 1}$, N.P. Quinn ${ }^{\mathrm{a}}$ and M. Jahanshahi ${ }^{\mathrm{a}, *}$ \\ ${ }^{a}$ Sobell Department of Motor Neuroscience and Movement Disorders, Institute of Neurology and the National \\ Hospital for Neurology and Neurosurgery, University College London, Queen Square, WC1N 3BG, London \\ ${ }^{\mathrm{b}}$ Cognitive, Perceptual and Brain Sciences, University College London, 26 Bedford Way, WClH OAP, London
}

Received 12 March 2008

Revised 28 January 2011

\begin{abstract}
In the elderly, fear of falling (FoF) can lead to activity restriction and affect quality of life (QoL). Our aim was to identify the characteristics of FoF in Parkinson's disease and assess its impact on QoL. We assessed FoF in 130 patients with Parkinson's disease (PD) on scales measuring perceived self-efficacy in performing a range of activities (FES), perceived consequences of falling (CoF), and activity avoidance (SAFFE). A significant difference was found in FoF between PD patients who had previously fallen and those who had not and between frequent and infrequent fallers. Patient-rated disability significantly influenced FoF. Difficulty in rising from a chair, difficulty turning, start hesitation, festination, loss of balance, and shuffling were the specific mobility problems which were associated with greater FoF in PD. Disability was the main predictor of FoF, additionally depression predicted perceived consequences of falling, while anxiety predicted activity avoidance. The FoF measures explained $65 \%$ of the variance of $\mathrm{QoL}$ in $\mathrm{PD}$, highlighting the clinical importance of FoF. These results have implications for the clinical management of FoF in PD.
\end{abstract}

Keywords: Fear of falling, Parkinson's disease, mobility, quality of life, falls

\section{Abbreviations}

$\begin{array}{cl}\text { ADL } & \text { Activities of daily living } \\ \text { CoF } & \text { Consequences of falling } \\ \text { FES } & \text { Falls Efficacy Scale } \\ \text { FoF } & \text { Fear of falling } \\ \text { H\&Y } & \text { Hoehn and Yahr stage } \\ \text { PD } & \text { Parkinson's disease } \\ \text { QoL } & \text { Quality of life } \\ \text { S\&E } & \text { Schwab and England disability rating } \\ \text { SAFFE } & \text { Survey of Activities and Fear of Falling } \\ & \text { in the Elderly }\end{array}$

\section{Introduction}

In elderly populations, fear of falling (FoF) is a serious problem over and above falling itself [1-3]. FoF is associated with poorer health, reduced mobility and social activity, greater frailty, balance and gait prob-

\footnotetext{
${ }^{1}$ These authors contributed equally to this work.

*Corresponding author. Tel.: +44 203108 0033; Fax: +44 20 7419 1860; E-mail: m.jahanshahi@ion.ucl.ac.uk.
}

lems, modified postural control, psychological distress in the form of anxiety and depression, poorer quality of life (QoL), and increased likelihood of nursing home admission [1-10]. FoF has been linked to subsequent falls [10-12] and vice versa, resulting in a spiraling incidence of both phenomena and subsequent functional decline $[1,9,10,13]$.

Investigation of FoF in Parkinson's disease (PD) has been limited, despite the high risk of falls in PD [11, $14,15]$ and the proposal that the propensity to fall and an incapacitating fear of future falls lead to a restriction of daily activities [9,10,16-18], and a loss of independence, leaving patients socially isolated and reducing quality of life [19]. Activity restriction is in itself a risk factor for further falls and can lead to physical problems including muscle atrophy and poorer balance [3, 20,21]. PD patients have less confidence in performing activities of daily living (ADL) without falling than age-matched controls, and FoF is correlated with clinical ratings of balance and gait impairment [16,18,19, 22]. Such a relationship would be expected since falling itself has been linked to balance impairment [11,23]. 
The validity of general FoF measures has been shown in PD [18]; however, FoF in PD may also be influenced by specific mobility problems, such as festination and freezing of gait [24] in addition to previous falls. PD treatments such as medication [25,26] and deep brain stimulation (DBS) $[27,28]$ also influence falls and FoF. Notwithstanding the importance of mobility problems, the contribution of non-motor symptoms such as anxiety and depression to FoF in PD is currently unclear. A strong association between affective variables and FoF has been found [29], as has an inter-relation between depression, anxiety, physical ability and FoF [30]. Recent data from Thomas et al. suggests that PD patients who fall frequently express less FoF than those who fall infrequently [24]. It is suggested that this may be due to previous experience of falls without adverse consequences and may be a valuable marker for patients who would benefit from special techniques to instill a more realistic perception of the risks and consequences of falls.

Single-item methodology for assessing FoF i.e., "Are you afraid of falling?" is not adequately sensitive to different aspects of FoF, since FoF can be conceptualised in many ways: diminished perceived self-efficacy in performing a range of activities [9,30-32], avoidance of activity [9], loss of confidence [33] and as a specific expression of anxiety $[9,34]$. The question of how FoF is best measured remains open $[4,35]$ and is of particular interest for the management of FoF in PD.

It has been previously reported that PD patients have greater FoF than similarly aged healthy controls [16]. FoF has also been noted as prevalent in progressive supranuclear palsy [36], degenerative cerebellar ataxia [37], multiple sclerosis [38] and other neurological conditions [11], but not extensively investigated. The sparsity of research on FoF, and the range of FoF measures used, makes comparison with previous studies of the healthy elderly population difficult (for a recent review of the use and validity of FoF questionnaires in healthy adult populations see [39]). Therefore, this study did not seek to explore the differences in FoF between PD patients and controls. Instead, our aim was a detailed investigation of the components and characteristics of FoF in a large sample of PD patients, with normative data available for comparison where appropriate. More specifically, the aims of the study were: (i) to undertake a multi-dimensional assessment of different aspects of FoF in PD and to identify the dominant features of FoF in terms of perceived self-efficacy, feared consequences of falling and range of activities avoided, (ii) to investigate the impact of disease stage, previ- ous falls, fall frequency and the contribution of specific mobility problems as well as depression and anxiety to FoF in PD, and (iii) to identify the contribution of FoF to QoL in PD.

\section{Methods}

The study was approved by the Ethics Committee of the National Hospital for Neurology and Neurosurgery (NHNN) and the Institute of Neurology. Informed consent was obtained from all participants.

\subsection{Sample}

Patients who had recently attended PD clinics at the NHNN were invited to participate, $68 \%$ of whom responded. An advertisement was placed in the Parkinson's Disease Society Newsletter, to which 60 patients replied. The majority of questions could be answered by marking the chosen response and no writing was required. 130 patients ( 84 male) completed the questionnaires. Their mean age was 66.7 (SD 8.52). The mean duration of illness was 12.1 years (SD 7.94). The mean self-rated H\&Y stage [40] for the sample was 2.63 (SD $=1.19)$.

\subsection{Measures}

\subsubsection{Stage of illness and disability}

The self-administered measures of disease stage and of disability were modified versions of the Hoehn and Yahr (H\&Y) scale [40]; with stage 1 indicating mild parkinsonism and stage 5 indicating the most severe disease, and the Schwab and England (S\&E) scale [41]; with 10 indicating complete independence and 0 indicating complete dependence. Agreement between clinician and self-ratings of stage of illness and disability in PD has been found to be high [42].

\subsubsection{History of falls}

Patients' history of falls was assessed as part of the gait and falls questionnaire [43]. Item 12: "How often do you fall?" Possible responses were $0=$ Never, 1 $=$ Very rarely - about once a year, $2=$ Rarely - about once a month, $3=$ Often - about once a week, $4=$ Very often - once a day or more.

\subsubsection{PD mobility checklist}

Patients indicated whether they experienced specific mobility symptoms (listed in Table 3 ). The terms start 
hesitancy, shuffling, freezing, festination, propulsion and retropulsion were explained in simple terms. Each symptom was rated as $0=$ absent, $1=$ mild, $2=$ moderate, 3 = severe, when on and off medication.

\subsubsection{Measures of Fear of Falling (FoF)}

Consequences of Falling $(\mathrm{CoF})$ : Using the validated CoF scale [44], patients rated twelve statements of the form "I think that if I fall over ..." on 4-point scale $(1=$ disagree strongly, $2=$ disagree, $3=$ agree, $4=$ agree strongly). The possible total score range was 1248 , with higher scores indicating greater concern about CoF. Two, six-item subscales (score range 6-24) were also calculated: damage to identity (CoF-DI), and loss of functional independence (CoF-LFI).

Falls Efficacy Scale (FES): Self-ratings of perceived efficacy in performing 10 non-hazardous activities of daily living without falling provided a validated measure of FoF [30]. The total FES score ranged from 10 (completely confident/no fear of falling) to 100 (not at all confident/high fear of falling).

Survey of activities and fear of falling in the elderly (SAFFE): Using the Modified Survey of Activities and Fear of Falling in the Elderly (SAFFE) $[9,44]$, patients rated 17 activities on whether they would avoid them in case they fell $(0=$ never avoid, $1=$ sometimes avoid, 2 = always avoid). The possible total score range was 0-34, with higher scores indicating higher avoidance of activities.

\subsubsection{Measures of mood}

Self-reported depression and anxiety were assessed using the 21 item Beck Depression Inventory (BDI) [45] and Beck Anxiety Inventory (BAI) [46] questionnaires respectively. Both questionnaires had 21 items, scored $0-3$, giving summary scores from 0 (no depression/anxiety) to 63 (greatest depression/anxiety).

\subsubsection{Assessment of quality of life (QoL)}

QoL was assessed with the PDQ-39 [47], a PDspecific measure, from which the summary index (the PDQ39-SI) was derived, with a range of 0-100. Higher scores reflect poorer QoL.

\subsection{Statistics}

Data from the three FoF measures was inspected for normality and transformed if necessary. Effects of $\mathrm{H} \& \mathrm{Y}$ stage and previous falls on measures of FoF were assessed using ANOVA, correlations between FoF measures were analyzed using Pearson's correlation
Table 1A

Consequence of Falling scale. Percentage of the sample who agreed or strongly agreed with each item. "I think that if I fall over. . ". Valid $\mathrm{N}$ ranged from 116 to 122

\begin{tabular}{lc}
\hline & $\begin{array}{c}\text { Percentage of sample } \\
\text { who endorsed item }\end{array}$ \\
\hline Damage to identity (CoF-DI) & \\
I will be embarrassed & $62.3 \%$ \\
I will be in pain & $53.8 \%$ \\
I will feel foolish & $51.5 \%$ \\
I will have difficulty getting up & $48.5 \%$ \\
I will lose my confidence & $43.8 \%$ \\
I will cause a nuisance & $33.8 \%$ \\
Loss of functional independence (CoF-LFI) & \\
I will not be able to cope alone & $35.4 \%$ \\
I will lose my independence & $31.5 \%$ \\
I will become disabled & $30.0 \%$ \\
I will be helpless & $26.9 \%$ \\
I cannot continue to be active & $25.4 \%$ \\
I will be severely injured & $20.0 \%$ \\
\hline
\end{tabular}

coefficient. Regression analysis was used to assess the proportion of variance of FoF measures explained by severity of illness and measures of mood and of QoL explained by FoF.

\section{Results}

The mean CoF score was $26.9(\mathrm{SD}=7.90, \mathrm{~N}=110)$. CoF "damage to identity" (DI) subscore (mean = 14.6, $\mathrm{SD}=4.29, \mathrm{~N}=114$ ) was significantly greater than the $\mathrm{CoF}$ "loss of functional independence" (LFI) subscore $($ mean $=12.5, \mathrm{SD}=4.34, \mathrm{~N}=116 ; \mathrm{t}(109)=7.75$, $p<0.0005,2$-tailed), reflecting the higher percentage of patients endorsing CoF-DI items (33.8\%-62.3\% per item) than CoF-LFI items $(20.0 \%-35.4 \%$ per item; independent t-test, $p<0.01$, 2-tailed) see Table $1 \mathrm{~A}$. Equivalent measurements of $\mathrm{CoF}$ in healthy controls are rare, but a significantly older group of healthy subjects (mean age $=80.7, \mathrm{SD} 4.25 ; \mathrm{N}=166, p<0.0001$, 2-tailed) reported very similar perceived CoF (CoF-DI $=14.4, \mathrm{SD}=3.8$; CoF-LFI $=12.4, \mathrm{SD}=4.0$; independent t-tests both $p>0.5$, 2-tailed) [44].

The mean FES score for the PD sample was 38.0 $(\mathrm{SD}=24.8, \mathrm{~N}=110)$. Studies of healthy subjects have reported greater self-efficacy (mean FES scores $=25.1, \mathrm{SD}=12.3 ; \mathrm{N}=56, p<0.001$, 2-tailed), i.e., lower FoF, despite sampling an older population (mean age $=78, p<0.0001,2$-tailed) [30]. Our sample also reported low perceived self-efficacy relative to previous PD samples (mean FES score = 24.96) [24]. This difference may be due to longer disease duration (12.1 vs. 7.6 years, $p<0.0001,2$-tailed) and a higher percentage 
Table 1B

Mean (SD) scores on the Falls Efficacy Scale. Valid N ranged from 121 to 125

\begin{tabular}{lc}
\hline Activity & $\begin{array}{c}\text { Confidence in performing activity without falling } \\
(1=\text { completely confident, 10= not at all confident })\end{array}$ \\
\hline Simple shopping & $4.38(3.28)$ \\
Light housekeeping & $4.30(3.07)$ \\
Preparing meals not requiring carrying heavy or hot objects & $4.23(3.15)$ \\
Getting dressed and undressed & $3.86(2.53)$ \\
Taking a bath or a shower & $3.77(2.66)$ \\
Walking around the house & $3.75(2.59)$ \\
Getting in and out of bed & $3.67(2.73)$ \\
Answering the door or telephone & $3.61(2.64)$ \\
Reaching into cabinets or closets & $3.41(2.56)$ \\
Getting in and out of a chair & $3.35(2.45)$ \\
\hline
\end{tabular}

Table 1C

Survey of Activities and Fear of Falling in the Elderly (SAFFE) Scale: Percentage of the sample who sometimes or always avoided each activity. Valid $\mathrm{N}$ ranged from 113 to 119

\begin{tabular}{lc}
\hline Activity & $\begin{array}{c}\text { Percentage of patients } \\
\text { who avoided activity }\end{array}$ \\
\hline Go out when it is slippery & $72.3 \%$ \\
Go to a place with crowds & $64.6 \%$ \\
Go out to a social event & $58.5 \%$ \\
Go for a walk & $53.8 \%$ \\
Travel by public transport & $52.3 \%$ \\
Go to the shops & $50.0 \%$ \\
Take a bath & $49.2 \%$ \\
Reach for something above head level & $48.5 \%$ \\
Walk half a mile & $43.8 \%$ \\
Clean your house & $41.5 \%$ \\
Bend down to get something & $40.8 \%$ \\
Visit a friend or relative & $39.2 \%$ \\
Go up and down stairs & $33.8 \%$ \\
Take a shower & $33.1 \%$ \\
Prepare simple meals & $26.2 \%$ \\
Go to the doctor or dentist & $18.5 \%$ \\
Walk around indoors & $16.2 \%$ \\
\hline
\end{tabular}

of fallers in our sample (61.5\% reporting previous falls vs. $41 \%$ reporting a fall in previous 6 months). Perceived self-efficacy was lowest for relatively complex activities and shopping, the only item that necessitates leaving the home, see Table 1B, a pattern seen in previous PD samples [18]. For further statistical analyses, FES scores were log-transformed to remove skew.

The mean SAFFE score was $10.2(\mathrm{SD}=6.95, N=$ 102), previous measures of SAFFE in PD have produced similar mean values (8.2-9.2 after conversion for different scoring) [18]. The most frequently avoided activities involved venturing outside the home (Table 1C). However, excursions with a specific purpose such as visiting a relative or the doctor were less commonly avoided. Li et al. assessed 256 elderly subjects (mean age 77.5, $\mathrm{SD}=5.0, p<0.0001$ ) on an 11 activity version of the SAFFE on both activity levels and FoF. These elderly controls reported similar avoidance of going out for a walk, especially when slippery.
Table 2

Mean (SD) values for fallers and non-fallers on measures of fear of falling CoF: Consequences of Falling Scale; CoF-DI: Consequences of Falling, damage to identity; CoF-LFI: Consequences of Falling, loss of functional independence; FES: Falls Efficacy Scale, SAFFE: Survey of Activities and Fear of Falling in the Elderly. Significance for FES is based on tests of logged FES scores

\begin{tabular}{lccc}
\hline Measure & Non-fallers & Fallers & p-value \\
\hline Age & $64.5(8.93)$ & $67.4(8.16)$ & 0.081 \\
Years since PD onset & $8.56(4.47)$ & $13.7(8.47)$ & 0.001 \\
Hoehn and Yahr stage & $2.30(1.04)$ & $2.77(1.16)$ & 0.034 \\
CoF & $24.5(7.71)$ & $28.4(7.84)$ & 0.018 \\
CoF-DI & $13.6(4.44)$ & $15.4(4.12)$ & 0.042 \\
CoF-LFI & $11.1(3.99)$ & $13.1(4.38)$ & 0.022 \\
FES & $30.8(25.1)$ & $40.4(23.4)$ & 0.010 \\
SAFFE & $7.77(6.19)$ & $11.5(7.01)$ & 0.010 \\
\hline
\end{tabular}

However, a large percentage of PD patients in our study reported avoiding going to places with crowds, including shops, whereas for elderly controls these are among the least feared activities [35].

Perceived consequences of falling were more severe in female PD patients than males $(\mathrm{CoF}: \mathrm{F}(1,108)=$ $5.14, p<0.03$ ), specifically a greater fear of damage to identity (CoF-DI: $\mathrm{F}(1,112)=9.90, p=0.002)$. There were no other significant effects of gender on FoF.

CoF, (logged) FES and SAFFE scores were significantly correlated $(p<0.0005)$ : CoF - FES $r=0.396$, CoF - SAFFE $r=0.660$, FES - SAFFE $r=0.596$.

\subsection{Previous falls and FoF}

$61.5 \%$ of patients reported previous falls, $30.0 \%$ had never fallen ( $8.5 \%$ did not respond to this item). $30.0 \%$ reported falling once a month or more and $13.8 \%$, once a week or more. ANOVAs showed that fallers had greater FoF on all measures than non-fallers (all $p<$ 0.05 , see Table 2). Fallers tended to be older $(p<$ 0.09 ) and had longer disease duration ( $p=0.001$ ) than non-fallers. As expected, fallers also had higher $\mathrm{H} \& \mathrm{Y}$ stage than non-fallers $(p<0.04)$, since higher $\mathrm{H} \& \mathrm{Y}$ 
stages are defined by the presence of balance problems, of which falls would be the clearest sign. To determine whether the effect of falls on FoF is mediated by these differences, we repeated the analysis using ANCOVAs, with duration of illness and H\&Y stage as covariates. Having controlled for these covariates, previous experience of falls did not significantly affect any measures of FoF (all $p>0.05$ ).

Contrary to the findings of Thomas et al. FoF did not diminish with fall frequency (see Fig. 1) [24]. Comparison of infrequent fallers (approximately 1 fall per month or fewer) with frequent fallers (approximately 1 fall per week or more) revealed greater FoF in frequent fallers on all measures of FoF except CoF-DI (Bonferroni corrected criterion $p<0.01$ : CoF $p<$ 0.007 , CoF-DI $p>0.1$, CoF-LFI $p<0.002$, FES $p<$ 0.002 , SAFFE $p<0.009$ ). However, inspection of the group of most frequent fallers revealed strikingly low minimum scores for $\mathrm{CoF}$ (minimum $=15$ ) and SAFFE $($ minimum $=0)$.

\subsection{Effects of specific PD mobility symptoms on FoF scores}

Table 3 shows differences in FoF scores as a function of presence or absence of 11 PD mobility problems in the "on" state. After Bonferroni correction $(p<$ 0.0045), significant effects on FoF scores were found for difficulty in rising from a chair, difficulty turning, start hesitation, festination, loss of balance, and shuffling. Perceived self-efficacy (measured by FES) appeared most sensitive to the presence of PD mobility symptoms.

\subsection{Predictors of FoF}

Multiple linear regressions were run with FoF measures as the dependent variables and H\&Y, S\&E, BDI and $\mathrm{BAI}$ as independent variables. For $\mathrm{CoF}$ these independent variables accounted for $43.5 \%$ of the variance; $\mathrm{S} \& \mathrm{E}$ disability rating $(\beta=-0.331, t=-3.67, p<$ $0.0005)$, and BDI ( $\beta=0.362, t=3.94, p<0.0005)$ were significant predictors of perceived consequences of falling (others $p>0.19$ ). For FES, the independent variables accounted for $41.2 \%$ of the variance and only $\mathrm{S} \& \mathrm{E}$ disability rating $(\beta=-0.461, t=-4.97, p<$ 0.0005 ) was a significant predictor of perceived selfefficacy (all others $p>0.12$ ). For SAFFE, $50.7 \%$ of the variance was explained by the independent variables; $\mathrm{S} \& \mathrm{E}$ disability rating $(\beta=-0.504, t=-5.67, p<$ $0.0005)$, and BAI $(\beta=0.205, t=2.27, p=0.025)$ were significant predictors of activity avoidance, as was BDI at trend level ( $\beta=0.165, t=1.84, p=0.069)$.

\subsection{Effect of FoF on $Q o L$}

CoF-DI, CoF-LFI, FES and SAFFE were entered as independent variables in a regression analysis with PDQ39-SI as the dependent variable. These measures of FoF collectively accounted for $65.2 \%$ of the variance in QoL. SAFFE $(\beta=0.399, t=3.44, p=0.001)$ and FES ( $\beta=0.240, t=2.51, p=0.015)$ were significant predictors of QoL. A dissociation was found between CoF-DI which was not a significant predictor of QoL ( $\beta=0.047, t=0.325, p>0.7)$ and CoF-LFI which approached significance $(\beta=0.291, t=1.99, p=$ 0.052 ) as a predictor of QoL.

\section{Discussion}

This study aimed to assess multiple components of FoF in PD and their relationship with fall history, PD symptoms and measures of mood. FoF was influenced by disability ( $S \& E)$, previous falls and the presence of specific PD mobility symptoms in addition to depression and anxiety. FoF, in turn, had a significant impact on QoL. These results also indicate of the value of the various FoF measures used to assess different aspects of FoF in PD patients, since intriguing differences emerged in how these scales related to measures of PD severity, PD symptoms and measures of mood.

Relative to previously published normative data from elderly healthy individuals our PD sample had greater fear of the consequences of falling and lower perceived self-efficacy. This is in agreement with previous studies, which found PD patients to report greater FoF [16]. Although the absence of a matched control group is a potential weakness of this study, our primary aim was the detailed investigation of the characteristics and components of FoF in PD and factors that contributed to it and how FoF, in turn, affected QoL. Therefore, we will focus on the discussion of these findings and the relevance of this information to clinical practice regarding the identification of FoF in PD and the strategies that should be used to prevent or ameliorate it.

That only moderate correlations appeared between different measures of FoF corroborates that they reflect different aspects of FoF [4]. A patient who believes they are likely to fall during a particular activity (as revealed by FES) does not necessarily avoid that activity, since they may consider the activity to be essential or the consequences of a fall to be minimal. Similarly, a patient who fears severe consequences of a fall (as measured by $\mathrm{CoF}$ ) does not necessarily believe that a fall is 

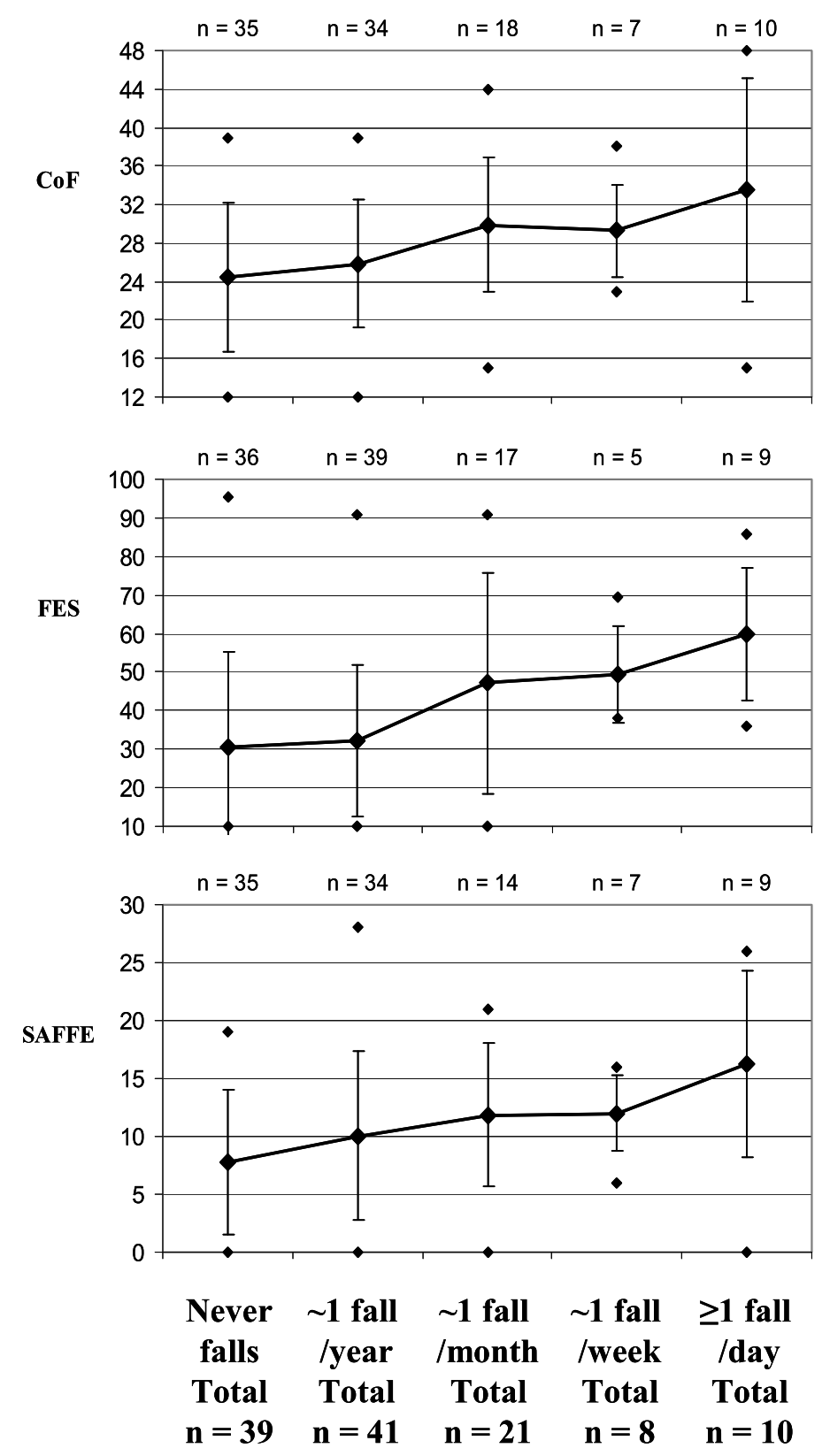

Fig. 1. Mean $( \pm \mathrm{SD})$ fear of falling $(\mathrm{FoF})$ values vs. frequency of falling. Higher values indicate greater FoF on all measures. Points above and below mean line indicate maximum and minimum values in each group. CoF: Consequences of Falling Scale; FES: Falls Efficacy Scale, SAFFE: Survey of Activities and Fear of Falling in the Elderly.

likely. Arguably, the SAFFE scale is the best measure of FoF since it measures actual activity avoidance due to FoF, the presence of which implies that (i) the patient believes that a fall is likely, (ii) they also believe that the fall will have undesirable consequences, and (iii) that these beliefs are strong enough to act on. That the SAFFE incorporates the crucial aspects of the FES and $\mathrm{CoF}$ measures in this way is supported by the relatively large correlations of FES with SAFFE, and CoF with SAFFE, compared to the correlation of FES with CoF.

Damage to identity was more commonly perceived as a likely consequence of falling than loss of functional independence, possibly reflecting existing limitations to functional independence due to PD. Fear of damage to identity was greater in women than men, corroborating previous findings [44], and similar to other 
Table 3

Mean (SD) scores on the CoF, FES, and SAFFE according to the presence/absence of specific mobility problems. Comparisons that reach significance at the Bonferroni corrected criterion of $p<0.0045$ are shown in bold, $p<0.05$ are marked "**. Significance for FES is based on tests of log-transformed FES scores.

\begin{tabular}{lcccc}
\hline Motor symptoms & & CoF & FES & SAFFE \\
\hline Difficulty rising from a chair & Present & $\mathbf{2 8 . 4}(\mathbf{7 . 7 5})$ & $\mathbf{4 1 . 8}(\mathbf{2 4 . 1})$ & $\mathbf{1 2 . 0}(\mathbf{6 . 8 1})$ \\
& Absent & $\mathbf{2 3 . 0}(\mathbf{6 . 3 8})$ & $\mathbf{2 3 . 1}(\mathbf{2 0 . 6})$ & $\mathbf{5 . 4 1}(\mathbf{4 . 6 7})$ \\
Difficulty turning while walking & Present & $\mathbf{2 8 . 8}(\mathbf{7 . 6 7})$ & $\mathbf{4 4 . 0}(\mathbf{2 3 . 4})$ & $\mathbf{1 2 . 5}(\mathbf{6 . 6 6})$ \\
& Absent & $\mathbf{2 4 . 2}(\mathbf{7 . 3 7})$ & $\mathbf{2 7 . 6}(\mathbf{2 3 . 3})$ & $\mathbf{7 . 1 0}(\mathbf{6 . 0 4})$ \\
Start hesitation & Present & $28.9(8.55)^{*}$ & $\mathbf{4 6 . 0}(\mathbf{2 5 . 2})$ & $\mathbf{1 2 . 1}(\mathbf{6 . 8 0})$ \\
& Absent & $24.5(5.99)^{*}$ & $\mathbf{2 7 . 1}(\mathbf{1 9 . 6})$ & $\mathbf{7 . 6 6}(\mathbf{5 . 9 8})$ \\
Festination & Present & $28.5(8.82)$ & $\mathbf{4 7 . 6}(\mathbf{2 4 . 7})$ & $\mathbf{1 2 . 8}(\mathbf{7 . 2 3})$ \\
\multirow{2}{*}{ Loss of balance } & Absent & $26.0(6.98)$ & $\mathbf{3 1 . 5}(\mathbf{2 2 . 7})$ & $\mathbf{8 . 3 4}(\mathbf{5 . 8 8})$ \\
& Present & $28.4(7.97)^{*}$ & $\mathbf{4 4 . 4}(\mathbf{2 4 . 2})$ & $11.6(7.13)^{*}$ \\
Shuffling & Absent & $23.8(6.41)^{*}$ & $\mathbf{2 4 . 9}(\mathbf{2 1 . 9})$ & $7.81(5.83)^{*}$ \\
\multirow{2}{*}{ Freezing } & Present & $27.6(8.59)$ & $\mathbf{4 3 . 0}(\mathbf{2 3 . 5})$ & $11.6(7.36)^{*}$ \\
& Absent & $25.9(6.13)$ & $\mathbf{2 7 . 6}(\mathbf{2 3 . 0})$ & $8.03(5.46)^{*}$ \\
Propulsion & Present & $28.2(8.66)$ & $43.3(25.6)^{*}$ & $11.4(7.15)^{*}$ \\
& Absent & $25.3(6.06)$ & $31.2(23.1)^{*}$ & $8.54(5.99)^{*}$ \\
Lack of arm swing & Present & $28.2(8.36)$ & $40.7(24.2)$ & $11.2(7.27)$ \\
& Absent & $25.4(7.16)$ & $31.9(23.3)$ & $8.67(6.00)$ \\
Retropulsion & Present & $26.9(7.70)$ & $38.2(23.7)$ & $10.6(7.12)$ \\
Stooped posture & Absent & $27.2(8.86)$ & $35.8(28.4)$ & $9.92(6.93)$ \\
& Present & $30.7(10.1)$ & $53.7(25.2)$ & $11.5(10.0)$ \\
& Absent & $26.9(7.74)$ & $36.2(23.8)$ & $10.3(6.60)$ \\
& Present & $27.6(8.10)$ & $38.6(24.0)$ & $10.7(7.37)$ \\
\hline
\end{tabular}

CoF: Consequences of Falling Scale; FES: Falls Efficacy Scale; SAFFE: Survey of Activities and Fear of Falling in the Elderly.

gender differences found in FoF $[1-3,11,18]$. Healthy elderly patients have reported that the greatest fear is associated with "going out when it is slippery", "taking a walk for exercise", and "reaching for something over your head" [35]. Our results indicate that similar activities are avoided by PD patients and that confidence decreases with increasing task complexity, but that situations with large numbers of people e.g., crowds, social events and public transport, are also avoided as shown in previous PD samples [18]. Previous work by our group has shown that such situations trigger freezing in a large percentage of patients [48]. Therefore, such situations may be avoided because they increase the likelihood of falling through freezing.

That fallers had significantly more advanced, and a longer duration of, PD corroborates previous studies [14], as does greater FoF in those who had already fallen $[13,18,25,49]$. Given the link between FoF and postural instability in PD patients [16,19], (as in controls [6]) this emphasizes the importance of ensuring that patients do not get into a recursive pattern of FoF and falls. Balance is important for the safe performance of many activities required to remain independent [50, 51] and so loss of balance was, predictably, related to lower perceived self-efficacy. If, as Thomas et al. speculate, experience of falls without adverse consequences leads to low FoF in frequent fallers we could predict that they would report a high expectation of falling during tasks (FES) but minimal expected consequences of falling (CoF) and low activity avoidance (SAFFE) [24]. Our data do not show this pattern overall; FoF increased with fall frequency on all measures except CoF-DI, on which fall frequency had no effect. Given that Thomas et al. measured perceived self-efficacy (FES), their findings are surprising in that they suggest that increased fall frequency is associated with erroneously increased confidence in performing tasks without falling. We note that some very frequent fallers (one fall a day or more) in our sample display very low $\mathrm{CoF}$ and SAFFE scores. These patients may merit further investigation either because they have developed effective strategies for reducing the consequences of falls, which beneficially reduce FoF and activity avoidance, or because they paradoxically show little apprehension regarding the consequences of falls, which may in turn lead to less cautious behaviour.

The presence of start hesitation and freezing (at $p<$ $0.05)$ were associated with greater FoF. Sudden and unpredictable gait blocks frequently result in falls [52]. Difficulty in walking prior to a fall is well recognized, and may be due not only to PD, but also related to comorbidities (such as osteoporosis) that are potentially 
treatable [52]. Festination had a significant effect on FoF, and it has been associated with frequent falls [53]. There was no significant difference in FoF according to presence/absence of stooped posture despite it being considered to increase the likelihood of forward falls, perhaps as the associated forward shift of the centre of gravity provides relative protection against a backward fall [54]. Difficulty rising from a chair and turning were also associated with greater FoF on all scales, identifying them as worthwhile targets for treatment by physiotherapy or other means.

An important finding in this study is that depression and anxiety had differential effects on FoF. Whereas self-rated disability was a predictor of FoF on all three scales, greater depression predicted perceived consequences of falling $(\mathrm{CoF})$, while anxiety predicted activity avoidance (SAFFE). This finding reflects the specific nature of the different components of FoF and suggests that direct treatment of depression is important for improving QoL [55] and perceived consequences of falling in PD, while treating anxiety is necessary for reducing FoF-related activity avoidance.

The influence of FoF on QoL appears to be as important as the contributions of disability, depression and anxiety [55]. That the SAFFE was the main predictor of QoL was expected since it directly measures patients' activity avoidance as a consequence of FoF, and QoL is also partly determined by patients' ability to engage in diverse activities. High SAFFE scores may identify PD patients who would benefit from therapeutic intervention relating to their FoF and avoidance behaviour. The complementary information provided by the three scales should provide a comprehensive assessment of FoF, with some components being more amenable to intervention through cognitive behavioural techniques than others. Our results suggest that, alongside exercise regimes and fall-related multifactorial interventions identified as effective in reducing FoF in PD [56, 57] and the wider elderly population [58], medical or cognitive behavioural treatment of depression and anxiety should improve FoF in PD. In addition, cognitive behaviour therapy to modify negative cognitions relating to perceived self-efficacy and consequences of falling and to overcome avoidance of activities may prove of value in management of FoF in PD.

\section{Acknowledgements}

We are grateful to all patients who participated.

This work was funded by the UK Parkinson's Disease Society.

\section{References}

[1] C.L. Arfken, H.W. Lach, S.J. Birge and J.P. Miller, The prevalence and correlates of fear of falling in elderly persons living in the community, Am J Public Health 84 (1994), 565-570.

[2] G.A.R. Zijlstra, J.C.M. van Haastregt, J.T.M. van Eijk, E. van Rossum, P.A. Stalenhoef and G.I.J.M. Kempen, Prevalence and correlates of fear of falling and associated avoidance of activity in the general population of community-living older people, Age Ageing 36 (2007), 304-309.

[3] B.J. Vellas, S.J. Wayne, L.J. Romero, R.N. Baumgartner and P.J. Garry, Fear of falling and restriction of mobility in elderly fallers, Age Ageing 26 (1997), 189-193.

[4] E.C. Jørstad, K. Hauser, C. Becker and S.E. Lamb, on behalf of the ProFaNE Group, Measuring the psychological outcomes of falling: a systematic review, J Am Geriatr Soc $\mathbf{5 3}$ (2005), 501-510.

[5] B.E. Maki, Gait changes in older adults: predictors of falls or indicators of fear? J Am Geriatr Soc 45 (1997), 313-320.

[6] A.L. Adkin, J.S. Frank, M.G. Carpenter and G.W. Peysar, Fear of falling modifies anticipatory postural control, Exp Brain Res 143 (2002), 160-170.

[7] J. Liddle and C. Gilleard, The emotional consequences of falls for older people and their families, Clin Rehabil 9 (1995), $110-114$.

[8] J.M. Chandler, P.W. Duncan, L. Sanders and S. Studenski, The fear of falling syndrome: relationship to falls, physical performance and activities of daily living in frail older persons, Top Geriatr Rehabil 11 (1996), 55-63.

[9] M.E. Lachman, J. Howland, S. Tennedst, A. Jette, S. Assmann and E.W. Peterson, Fear of falling and activity restriction: the Survey of Activities and Fear of Falling in the Elderly (SAFE), J Gerontol B Psychol Sci Soc Sci 53 (1998), 43-50.

[10] R.G. Cumming, G. Salkeld, M. Thomas and G. Szonyi, Prospective study of the impact of fear of falling on activities of daily living, SF-36 scores and nursing home admission, $J$ Gerontol A Biol Sci Med Sci 55 (2000), 299-305.

[11] H. Stolze, S. Klebe, C. Zechlin, C. Baecker, L. Friege and G. Deuschl, Falls in frequent neurological diseases. Prevalence, risk factors and aetiology, J Neurol 251 (2004), 79-84.

[12] M.K.Y. Mak and M.Y.C. Pang, Fear of falling is independently associated with recurrent falls in patients with Parkinson's disease: a 1-year prospective study, J Neurol 256 (2009), 1689-1695.

[13] S.M. Friedman, B. Munoz, S.K. West, G.S. Rubin and L.P. Fried, Falls and fear of falling: which comes first? A longitudinal prediction model suggests strategies for primary and secondary prevention, J Am Geriatr Soc 50 (2002), 1329-1335.

[14] Y. Balash, C. Peretz, G. Leibovich, T. Herman, J.M. Hausdorff and N. Giladi, Falls in outpatients with Parkinson's disease. Frequency, impact and identifying factors, J Neurol 252 (2005), 1310-1315.

[15] R.M. Pickering, Y.A.M. Grimbergen, U. Rigney, A. Ashburn, G. Mazibrada, B. Wood, P. Gray, G. Kerr and B.R. Bloem, A meta-analysis of six prospective studies of falling in Parkinson's disease, Mov Disord 22 (2007), 1892-1900.

[16] A.L. Adkin, J.S. Frank and M.S. Jog, Fear of falling and postural control in Parkinson's disease, Mov Disord 18 (2003), 496-502.

[17] B.R. Bloem, Y.A.M. Grimbergen, M. Cramer, M. Willemsen and A.H. Zwinderman, Prospective assessment of falls in Parkinson's disease, J Neurol 248 (2001), 950-958.

[18] M.H. Nilsson, A. Drake and P. Hagell, Assessment of fallrelated self-efficacy and activity avoidance in people with Par- 
kinson's disease, BMC Geriatrics 10 (2010), 78.

[19] F. Franchignoni, E. Martignoni, G. Ferriero and C. Pasetti, Balance and fear of falling in Parkinson's disease, Parkinsonism Relat Disord 11 (2005), 427-433.

[20] A.J. Campbell, M.J. Borrie and G.F. Spears, Risk factors for falls in a community-based prospective study of people 70 years and older, J Gerontol 44 (1989), 112-117.

[21] J. Howland, E.W. Peterson, W.C. Levin, L. Fried, D. Pordon and S. Bak, Fear of falling among community-dwelling elderly, J Aging Health 5 (1993), 229-243.

[22] T. Herman, N. Inbar-Borovsky, M. Brozgol, N. Giladi and J.M. Hausdorff, The Dynamic Gait Index in healthy older adults: the role of stair climbing, Fear of Falling and Gender Gait Posture 29 (2009), 237-241.

[23] W.C. Koller, S. Glatt, B. Vetere-Overfield and R. Hassanein, Falls and Parkinson's disease, Clin Neuropharmacol 12 (1989), 98-105.

[24] A.A. Thomas, J.M. Rogers, M.M. Amick and J.H. Friedman, Falls and the falls efficacy scale in Parkinson's disease, $J$ Neurol 257 (2010), 1124-1128.

[25] K. Robinson, A. Dennison, D. Roalf, J. Noorigian, H. Cianci, L. Bunting-Perry, P. Moberg, G. Kleiner-Fisman, R. Martine, J. Duda, J. Jaggi and M. Stern, Falling risk factors in Parkinson's disease, NeuroRehabilitation 20 (2005), 169-182.

[26] G.K. Kerr, C.J. Worringham, M.H. Cole, P.F. Lacherez, J.M. Wood and P.A. Silburn, Predictors of Future Falls in Parkinson Disease Neurology 75 (2010), 116-124.

[27] M.H. Nilsson, P.-A. Fransson, G.-B. Jarnlo, M. Magnusson and S. Rehncrona, The effects of high frequency subthalamic stimulation on balance performance and fear of falling in patients with Parkinson's disease, J Neuroeng Rehabil 6 (2009), 13.

[28] M.H. Nilsson, S. Rehncrona and G.-B. Jarnlo, Fear of falling and falls in people with Parkinson's disease treated with deep brain stimulation in the subthalamic nuclei, Acta Neurol Scand, no.doi: 10.1111/j.1600-0404.2010.01418.x.

[29] M.D. Gagnon, A.J. Flint, G. Naglie and G.M. Devins, Affective correlates of fear of falling in elderly persons, $A m J$ Geriatr Psychiatry 13 (2005), 7-14.

[30] M.E. Tinetti, D. Richman and L. Powell, Falls efficacy as a measure of fear of falling, J Gerontol 45 (1990), 239-243.

[31] R.W. Kressig, S.L. Wolf, R.W. Sattin, M. O'Grady, A. Greenspan, A. Curns and M. Kutner, Associations of demographic, functional and behavioural characteristics with activityrelated fear of falling among older adults transitioning to frailty, J Am Geriatr Soc 49 (2001), 1456-1462.

[32] Fuzhong, E. McAuley, K.J. Fisher, P. Harmer, N. Chaumeton and N.L. Wilson, Self-efficacy as a mediator between fear of falling and functional ability in the elderly, J Aging Health $\mathbf{1 4}$ (2002), 452-466

[33] L.E. Powell and A.M. Myers, The activities-specific balance and confidence (ABC) scale, J Gerontol A Biol Sci Med Sci 50A (1995), 28-34.

[34] J. Murphy and B. Isaacs, The post-fall syndrome. A study of 36 elderly patients, Gerontology 28 (1982), 265-270.

[35] F. Li, J. Fisher, P. Harmer, E. McAuley and N.L. Wilson, Fear of falling in elderly persons: associations with falls, functional ability and quality of life, J Gerontol B Psychol Sci Soc Sci 58B (2003), 283-290.

[36] B.R. Bloem, M. Munneke, G. Mazibrada, A. Schrag, R.Viswanathan, A.J. Lees and N.P. Quinn, The nature of fear of fallin in Progressive Supranuclear Palsy, Mov Disord 19 (2004), 359-360.
[37] B.P.C. van de Warrenburg, J.A.G. Steijns, M. Munneke, B.P.H. Kremer and B.R. Bloem, Falls in Degenerative Cerebellar Ataxia, Mov Disord 20 (2005), 497-500.

[38] E.W. Peterson, C.C. Cho and M.L. Finlayson, Fear of falling and associated activity curtailment among middle aged and older adults with multiple sclerosis, Mult Scler 13 (2002), $1168-1175$.

[39] D.S. Moore and R. Ellis, Measurement of fall-related psychological constructs among independent-living older adults: a review of the research literature, Aging Ment Health 12 (2008), 684-699.

[40] M.M. Hoehn and M.D. Yahr, Parkinsonism: onset progression and mortality, Neurology 17 (1967), 427-442.

[41] R.S. Schwab and A.C. England, Projection technique for evaluating surgery in Parkinson's disease, in: F.J. Gillingham, I.M.L. Donaldson, eds, Third symposium on Parkinson's disease. Edinburgh: Livingstone 1969, pp. 152-157.

[42] A. Schrag, M. Jahanshahi and N.P. Quinn, What contributes to depression in Parkinson's disease? Psychol Med 31 (2001), 65-73.

[43] N. Giladi, H. Shabtain, E.S. Simon, S. Biran, J. Tal and A.D. Korczyn, Construction of freezing of gait questionnaire for patients with Parkinsonism, Parkinsonism Relat Disord 6 (2000), $165-170$.

[44] L. Yardley and H. Smith, A prospective study of the relationship between feared consequences of falling and avoidance of activity in community living older people, Gerontologist $\mathbf{4 2}$ (2002), 17-23.

[45] A.T. Beck, C.H. Ward, M. Mendelson, J. Mock and J. Erbaugh, An inventory for measuring depression, Arch Gen Psych $\mathbf{4}$ (1961), 53-63.

[46] A.T. Beck, N. Epstein, G. Brown and R.A. Steer, An inventory for measuring clinical anxiety: psychometric properties, $J$ Consult Clin Psychol 56 (1988), 893-897.

[47] V. Peto, C. Jenkinson, R. Fitzpatrick and R. Greenhall, The development and validation of a short measure of functioning and well-being for individuals with Parkinson's disease, Qual Life Res 4 (1995), 241-248.

[48] S. Rahman, H.J. Griffin, N.P. Quinn and M. Jahanshahi, The factors that induce or overcome freezing of gait in Parkinson's disease, Behav Neurol 19 (2008), 127-136.

[49] M.K.Y. Mak and M.Y.C. Pang, Balance confidence and functional mobility are independently associated with falls in people with Parkinson's disease, J Neurol 256 (2009), 742-749.

[50] B.H. Wood, J.A. Bilclough A. Bowron and R.W. Walker, Incidence and prediction of falls in Parkinson's disease: a prospective multidisciplinary study, J Neurol Neurosurg Psychiatry 72 (2002), 721-725.

[51] S.E. Lamb, L. Ferrucci, S. Volapto, L.P. Fried and J.M. Guralnik, for the Women's Health and Aging Study, Risk factors for falling in home-dwelling older women with stroke, Stroke 34 (2003), 494-501.

[52] B.R. Bloem, J.M. Hausdorff, J.E. Visser and N. Giladi, Falls and freezing of gait in Parkinson's disease: a review of two interconnected, episodic phenomena, Mov Disord 19 (2004), 871-884.

[53] N. Giladi, H. Shabtai, E. Rozenberg and E. Shabtai, Gait festination in Parkinson's disease, Parkinsonism Relat Disord 7 (2001), 135-138.

[54] B.R. Bloem, J.G. van Dijk and D.J. Beckley, Are automatic postural responses in patients with Parkinson's disease abnormal due to their stooped posture? Exp Brain Res 124 (1999), $481-488$. 
[55] S. Rahman, H.J. Griffin, N.P. Quinn and M. Jahanshahi, Quality of life in Parkinson's disease: the relative importance of the symptoms, Mov Disord 23 (2008), 1428-1434.

[56] B.D. Cakit, M. Saracoglu, H. Genc, H.R. Erdem and L. Inan, The effects of incremental speed-dependenttreadmill training on postural instability and fear of falling in Parkinson's disease, Clin Rehabil 21 (2007), 698-705.

[57] N.E. Allen, C.G. Canning, C. Sherrington, S.R. Lord, M.D.
Latt, J.C.T. Close, S.D. O'Rourke, S.M. Murray and Victor S.C. Fung, The effects of an exercise program on fall risk factors in people with Parkinson's disease: a randomized controlled trial, Mov Disord 25 (2010), 1217-1225.

[58] G.A.R. Zijlstra, J.C.M. van Haastregt, E. van Rossum, J.T.M. van Eijk, L. Yardley and G.I.J.M. Kempen, Interventions to reduce fear of falling in community-living older people: a systematic review, J Am Geriatr Soc 55 (2007), 603-615. 


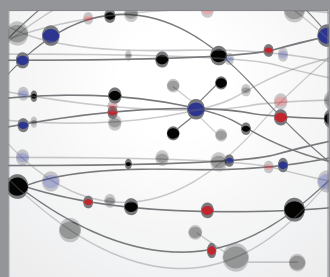

The Scientific World Journal
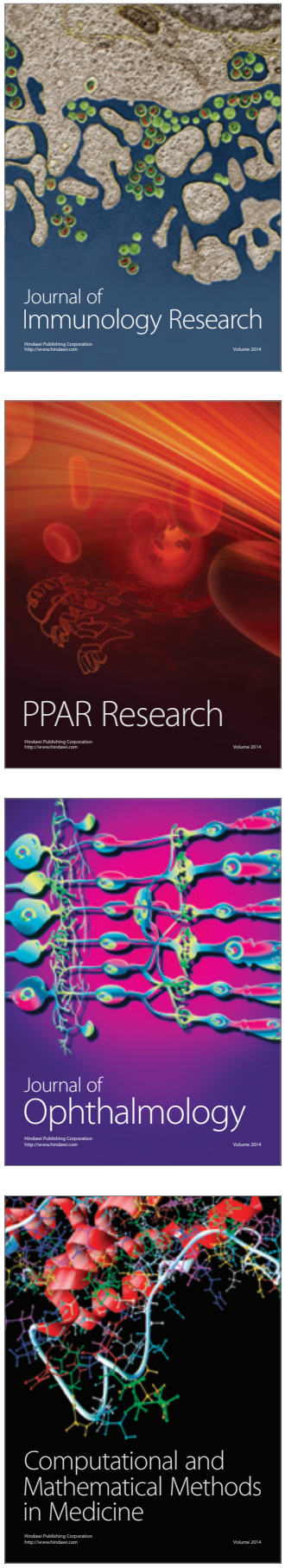

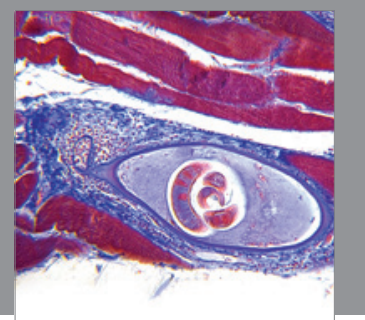

Gastroenterology

Research and Practice
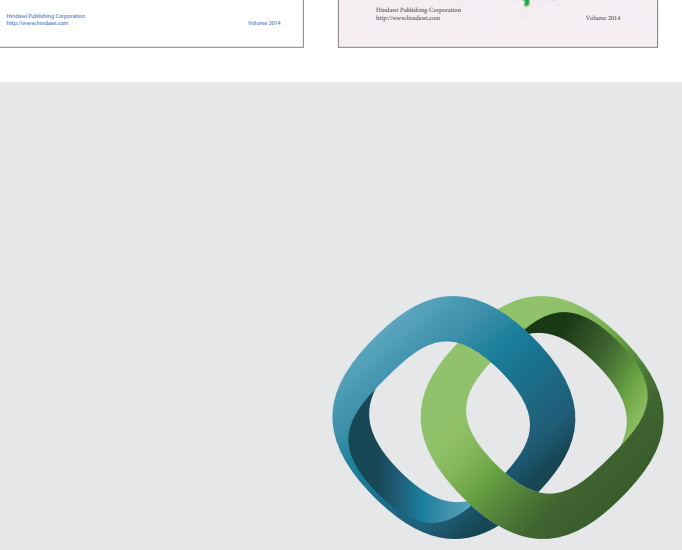

\section{Hindawi}

Submit your manuscripts at

http://www.hindawi.com
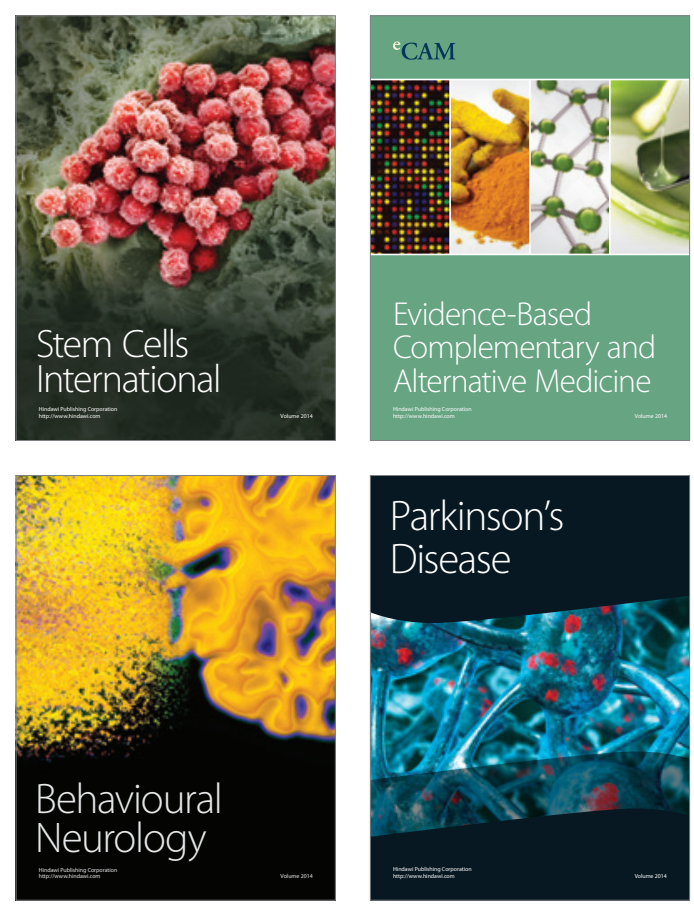

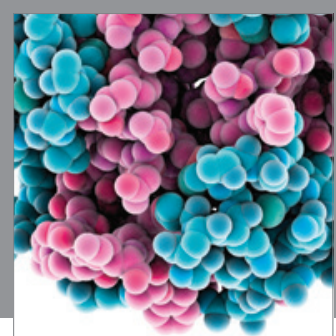

Journal of
Diabetes Research

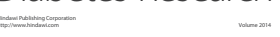

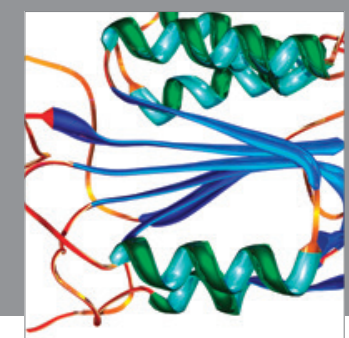

Disease Markers
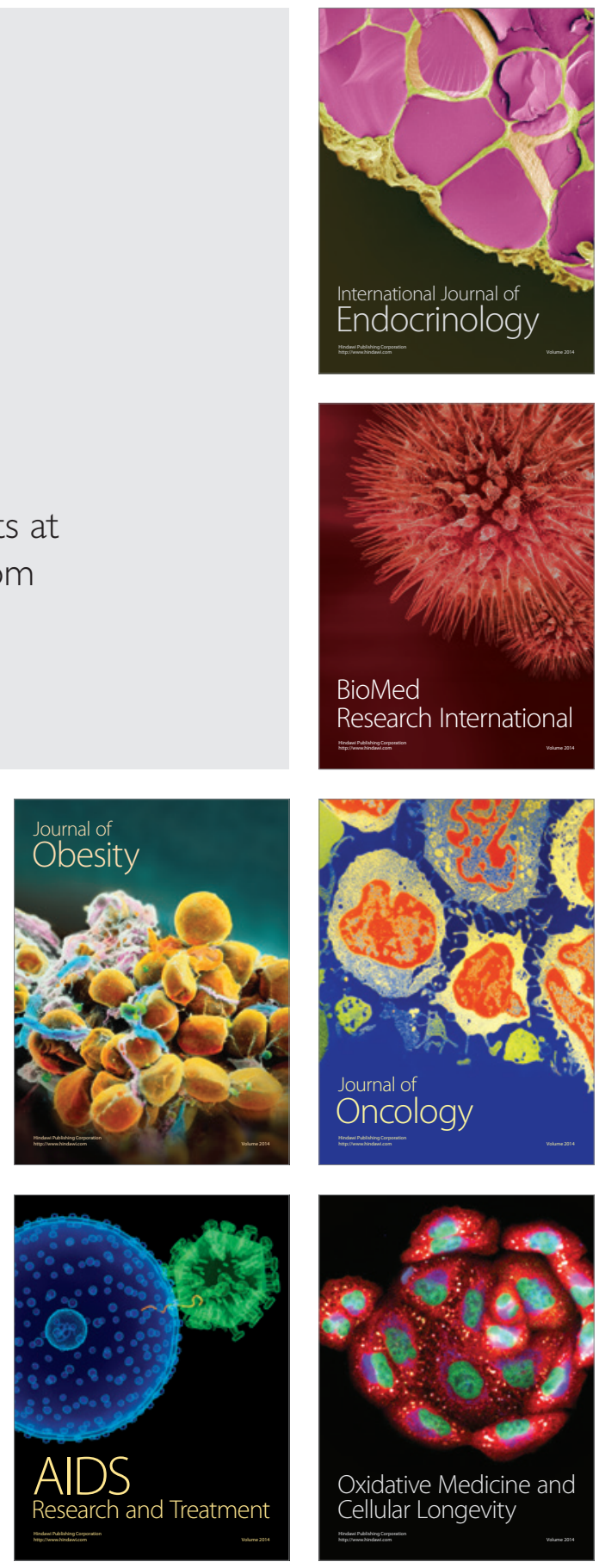